\title{
EXPERIMENTAL STUDY ON JOINT STIFFNESS WITH VISION-BASED SYSTEM AND GEOMETRIC IMPERFECTIONS OF TEMPORARY MEMBER STRUCTURE
}

\author{
Cong LIU*, Lin HE, Zhenyu WU, Jian YUAN \\ School of Civil Engineering, Harbin Institute of Technology, Harbin, Heilongjiang 150090, China \\ Key Lab of Structures Dynamics Behavior and Control of the Ministry of Education, \\ Harbin Institute of Technology, Harbin, Heilongjiang 150090, China
}

Received 26 September 2017; accepted 27 November 2017

\begin{abstract}
In this paper, tests of plug-pin joints are conducted in order to obtain their mechanical parameters, including semi-rigid property. To solve the difficulties of multi-point displacement measurements for small joints, this investigation proposes a visionbased measurement system based on the principle of binocular stereo vision to improve measurement accuracy. Accurate subpixel location is achieved according to a template-matching algorithm based on grayscale. Joint performance, including horizontal bar joint tension and compression, semi-rigidity between horizontal bars and upright rods and bracing tension and compression, is investigated in order to acquire joint failure modes as well as load and displacement (or moment and rotation angle) curves. Through data fitting, multi-linear simplified models are proposed to illustrate the joints' mechanical performance. This paper also investigates geometric imperfection of temporary member structure with plug-pin joints based on several substructure models and temporary grandstand units using a total station theodolite. The probabilistic models of initial member out-of-straightness and story frame out-of-plumb have been acquired, which can be used into Monte Carlo simulation to create stochastic model of the temporary member structure.
\end{abstract}

Keywords: temporary member structure, plug-pin joint, vision-based measurement system, multi-linear simplified model, initial geometric imperfection, probabilistic model.

\section{Introduction}

Temporary member structures (TMS) are a type of structure composed of slender members and corresponding connection joints. They can be quickly erected and dismantled. Previous applications of these structures include scaffolding systems (Beale 2014), while now they are popular in the field of sports and culture, such as temporary grandstands, stages and ski slopes. Joints are the weakest elements of TMS and the structural components are more resistant to loads than the connections between them. This is caused by the producers' efforts to facilitate the assembly of elements, the relatively complex stress conditions, as well as the elements being connected to the joints at diverse angles. The mutual interactions between structural elements result in stress on the joints while the stress values often exceeded their yield capacity. Previous research has shown that the behaviour of connection devices has a significant influence on the performance of TMS (Liu et al. 2016). TMS connection joints have many types, including couple, cuplock, plug-pin and disc-type (Figure 1). This paper is aimed at TMS with plug-pin joints (Figure 1c), which are far more convenient and efficient. This kind of joint serves mainly as the linkage between upright rods, horizontal bars and bracings. Tests are necessary in order to obtain the mechanical behaviour of these joints, and to serve as guidance for the numerical analysis of TMS.

Several tests have been conducted on TMS connection joints. For tube-couple joints, the rotational and slipping stiffness of the right-angle couple were the main parameters, and initial rotational stiffness could be used in numerical simulations of the structure (Liu et al. 2016). Research about cuplock joints has shown that the connection between vertical and horizontal members was semi-rigid and could be best described by a tri-linear moment-rotation curve (Chandrangsu, Rasmussen, 2011a). When the load was small, the cuplock connections exhibited looseness with little rotational stiffness (Godley,

${ }^{*}$ Corresponding author. E-mail: liucong@hit.edu.cn 


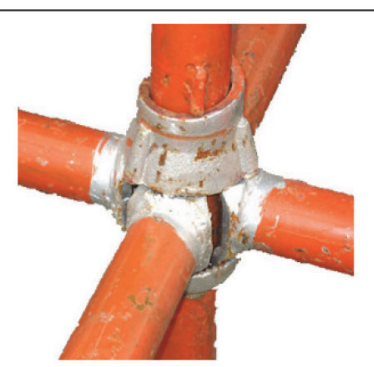

a. Cuplock joint

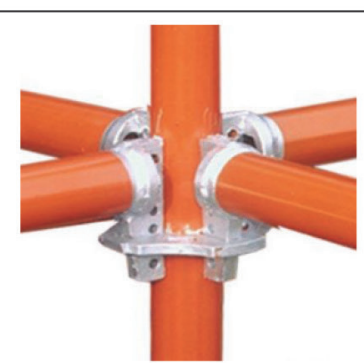

b. Slip joint

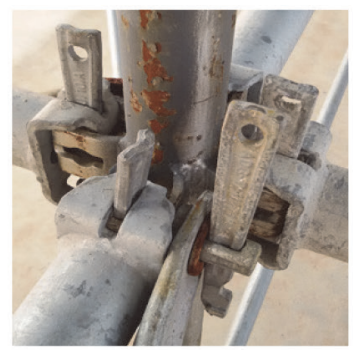

c. Plug-pin joint

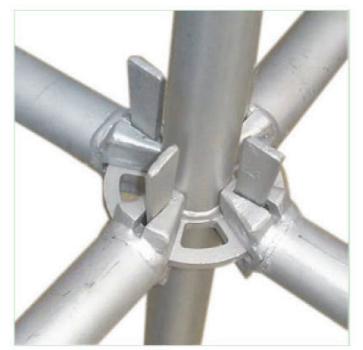

d. Disc-type joint

Figure 1. Connection joints of TMS

Beale 1997). For wedge-type joints, the joints of the diagonal bracings could be assumed to be hinges. The bending stiffness of these joints at both ends of the horizontal bars showed weak semi-rigidity and adjustability with critical loads (Peng et al. 2013).

During the joint tests, multi-point displacement measurements are necessary to quantify joint deformation. Traditional displacement sensors, such as linear variable differential transformers (LVDT), require a stationary platform as the measurement reference. For this wedge-type joint, the arrangements of two or three LVDTs are difficult, so the non-contact measurement method is a newer and better option to conduct to these joint tests. The non-contact measurement systems rely on technologies, such as lasers, radar and GPS, as well as the processing and analysis of images obtained by video technology (Lee, Shinozuka 2006; Chang, Ji 2007; Morlier et al. 2007; Yun et al. 2011; Lord, Mccormick 2012) or digital photography (Bell et al. 2012; Jáuregui et al. 2003; Jiang et al. 2008). Photogrammetry, which has been widely used for static and dynamic displacement measurement, is a measurement technique that uses photographs to establish the geometrical relationship between an object and its photographic images (Di et al. 2011). Close range photogrammetry technology has been utilized in civil engineering applications such as bridge measurement (Jáuregui et al. 2003; Jiang et al. 2008; Fukuda et al. 2010). Armesto et al. (2009) presented a methodology for the evaluation of historic timber structures, and a photogrammetric modeling procedure was used to measure the geometry of the structural elements of a timber roof. Fu and Moosa (2002) used monochromatic images acquired from a CCD camera to measure the static deformation profile of a beam. A sub-pixel edge deflection technique was adopted, together with fitting, to locate damage in the beam. Chang and Ji (2007) used two commercial-grade digital video cameras to achieve a three-dimensional structural vibration measurement with low-frequency range.

The key features of TMS systems, their temporality and reusability, require structural members to be used repeatedly, which gradually contributes to initial member out-of-straightness. Furthermore, greater joint gap and workers' assembly quality also result in TMS initial story out-of-plumb being more significant than other steel struc- tures. Initial geometric imperfections are typically considered in advanced analyses (Kala 2012; Kala et al. 2017). Three methods of modeling imperfections were applied, including the scaling of eigen buckling modes (EBM), the application of notional horizontal forces and the direct modeling of initial geometric imperfections (Chan et al. 2005). EBM is widely used for these structures, which involves scaling one or more critical elastic buckling modes and adding the scaled displacements to the perfect geometry. While the number of buckling modes and the corresponding scaling factors were uncertain, measurements of support scaffold systems with cuplock joints revealed imperfections, such as standard out-of-straightness (obeying lognormal distribution) and story out-of-plumb (with normal distribution) (Chandrangsu, Rasmussen 2011a). In order to resolve the issue of modeling geometric imperfections for TMS with wedge type joints, the actual data of geometric imperfections are needed to identify the probability distribution which can be considered by Monte Carlo method (Bielewicz, Goórski 2002). Both of geometric imperfections and joint stiffness are indispensable to establish three-dimensional advanced analysis models of TMS (Chandrangsu, Rasmussen 2011b).

In this paper, a new low-cost vision-based measurement system was developed to monitor multi-point dynamic displacements during joint tests. For plug-pin joints, 19 tests have been conducted to study their tensile, compression and semi-rigid properties. In addition, a total of 91 measurements of upright rod out-of-straightness and 45 measurements of story out-of-plumb were taken and the corresponding probability distributions acquired.

\section{Vision-based measurement system}

\subsection{Architecture}

The proposed measurement system was comprised of the components presented in Figure 2. Two digital cameras were equipped with a COMPUTAR H0514-MP2 lens and DH-HV5051UM/UC-M sensor. A $10 \mathrm{~mm} \times 10 \mathrm{~mm}$ black and white square planar pattern was used for camera calibration. An automatic image acquisition and processing software was developed. Two halogen lamps were used to provide sufficient illumination. 


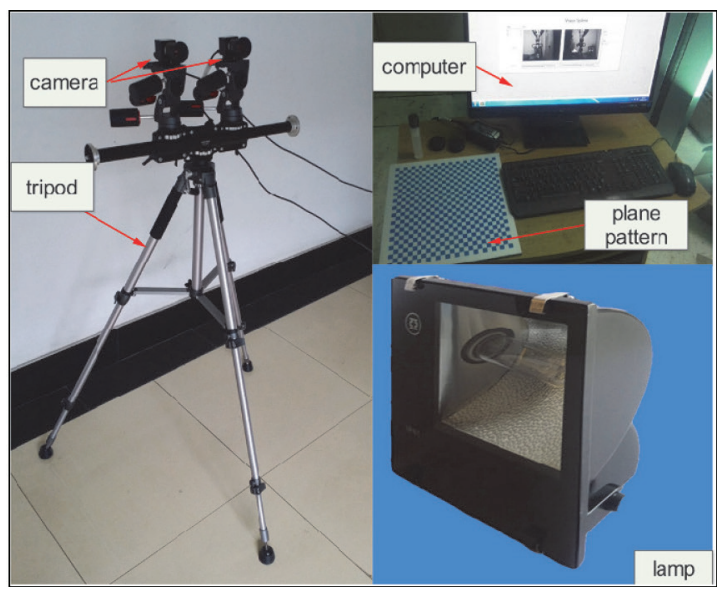

Figure 2. The vision-based measurement system

\subsection{Calibration}

Camera calibration was used to obtain the camera's intrinsic and extrinsic parameters. For close range photogrammetry using cameras, on-site calibration has become popular ever since effective techniques were developed. These techniques can be classified into two categories: photogrammetric calibration and self-calibration. For photogrammetric calibration, a calibration object with precisely known geometry was required. For self-calibration, bundle triangulation was performed using a network of highly convergent overlapping images. In this study, the plane-based camera calibration method (Tsai 1987) that requires only $2 \mathrm{D}$ control information was adopted. This technique uses a $10 \mathrm{~mm} \times 10 \mathrm{~mm}$ black and white square plane calibration pattern printed from a laser printer.

After the test model and measurement system were equipped, the camera calibration was conducted. Then, the digital cameras were turned on and the calibration software interface was opened (Figure 3). A plane pattern was placed in front of the test model and visibly displayed in two boxes of the screen. Once the images were clear enough, the "OK" button was clicked and the two images were saved. The plane pattern position was continuously adjusted until 10 pairs of images were acquired.

For this camera, the pinhole model (Ghosh, Mudur 1995) was used, which can be described as:

$$
\begin{gathered}
\lambda \mathbf{m}=\mathbf{K R}[\mathbf{I} \mathbf{t}] \mathbf{M} ; \\
\mathbf{K}=\left[\begin{array}{ccc}
k_{u} & s & u_{0} \\
0 & k_{v} & \mathrm{U}_{0} \\
0 & 0 & 1
\end{array}\right],
\end{gathered}
$$

where $\mathbf{m}=(u, v, 1)$ is the homogeneous vector of a point in the image coordinate which is defined by pixels; $\mathbf{R}$ is the rotation matrix and $\mathbf{t}$ is the translation vector; $\mathbf{M}=(X, Y, Z, 1)$ is the homogeneous vector of the point in the global coordinate system; $\lambda$ is the scale factor; $\mathbf{K}$ is the camera calibration matrix which contains five intrinsic parameters of a camera; $k_{u}$ and $k_{v}$ are focal lengths; $S$ is the skew parameter; $u_{0}$ and $v_{0}$ are coordinates of the principle points in terms of pixel dimensions.

Based on the pinhole model, the calibration of Zhang (2000) was applied because this method takes lens distortion into account. Generally, five to seven images are enough to obtain the precise values, but 10 images were collected in case of lower light quality.

\subsection{Measurement processing}

After the test model was equipped, several markers were pasted onto the test model position of interest. Some of them were used for monitoring displacement and others for correction in case of equipment impact. Markers were made using A4 paper with a black dot $(\mathrm{D}=5 \mathrm{~mm})$ and images with a frequency of $3.2 \mathrm{~Hz}$ were acquired.

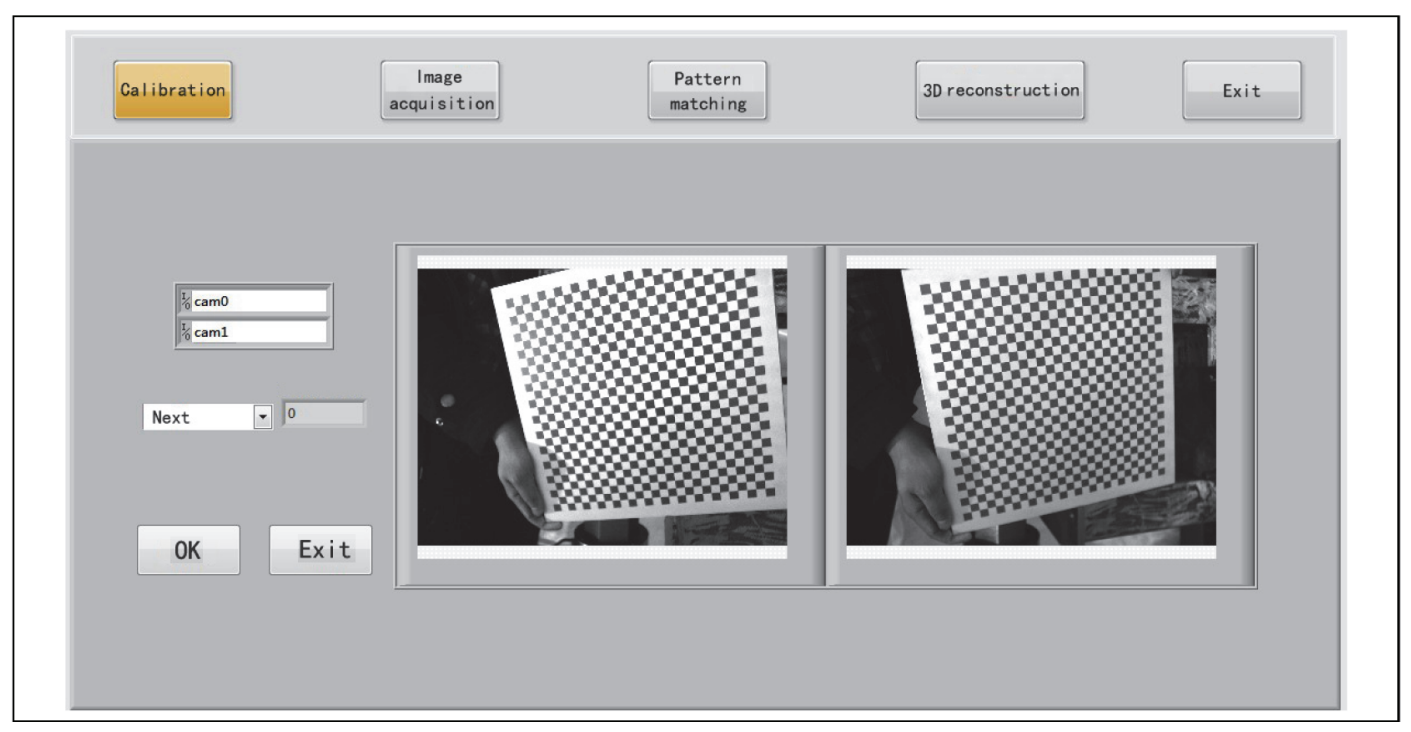

Figure 3. Interface of calibration 


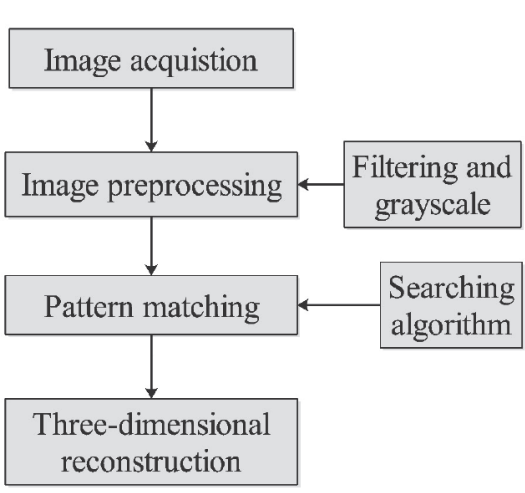

Figure 4. The image processing flow

The image processing flow is shown in Figure 4.

The target coordinate acquisition process based on template matching is as follows:

1. Image acquisition. Store the images acquired by the left and right camera in the specified folders;

2. Image pre-processing. Do the image filtering and grayscale processing to preparation for pattern matching;

3. Pattern matching. To obtain the matching templates at the measurement points, and write the matching information into the image in the PNG format. And then extract the pixel coordinates of measurement points respectively from the left and right images according to the pattern matching principle based on grayscale. At last, store the matching results in the shift register and provide the initial search region for next matching operation;

4. Three-dimensional reconstruction. Get the spatial 3D coordinates of the measuring points on the basis of calibration results and matching results.

A template-matching algorithm based on grayscale was developed. The templates for markers were extracted from the images and an accurate sub-pixel location was achieved. Normalized cross-correlation was adopted as the similarity measurement method for template matching. In order to improve matching efficiency, the best matching point was determined starting with the matching position of the last image as the points move continuously.

\subsection{Test verification}

A vibration test of the cantilever beam was conducted to verify the accuracy of this system. Figure 5 shows the test device, in which the cantilever beam was made of a steel plate with the dimensions of $80 \mathrm{~mm} \times 20 \mathrm{~mm} \times 2 \mathrm{~mm}$ and clamped onto the bracket. A rectangular steel plate measuring $20 \mathrm{~mm} \times 20 \mathrm{~mm} \times 2 \mathrm{~mm}$ was welded onto the end of the cantilever beam. ALVDT was fixed onto the rectangular steel plate by a U-shaped frame.

During the test, a slight vibration of the cantilever beam was created with the tip displacement being measured by both the LVDT and vision-based measurement system. The frequency of the LVDT was $20 \mathrm{~Hz}$. Figure 6

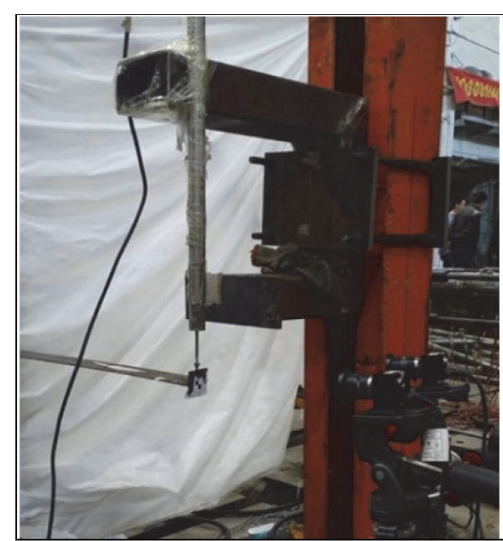

Figure 5. Test device for accuracy verification

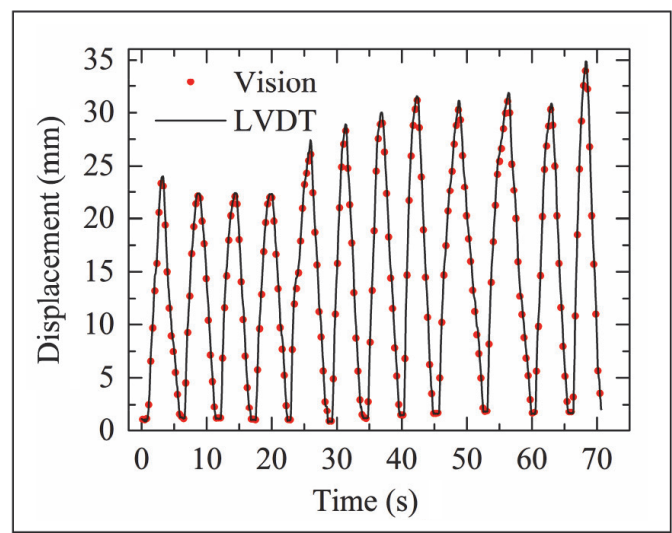

Figure 6. Tip displacement of cantilever beam

shows the congruent results measured by both the visionbased measurement system and LVDT. The average error in measurement between the two results was $0.16 \mathrm{~mm}$ and the standard deviation was $0.31 \mathrm{~mm}$.

\section{Joint tests}

\subsection{The structure of the joint model}

The function of this plug-pin joint is served by four $\mathrm{U}$-shaped latches which were welded to the pipe of the upright rod at $0.5 \mathrm{~m}$ intervals (Figure 7). Individual upright rods were connected by means of a pivot. Each

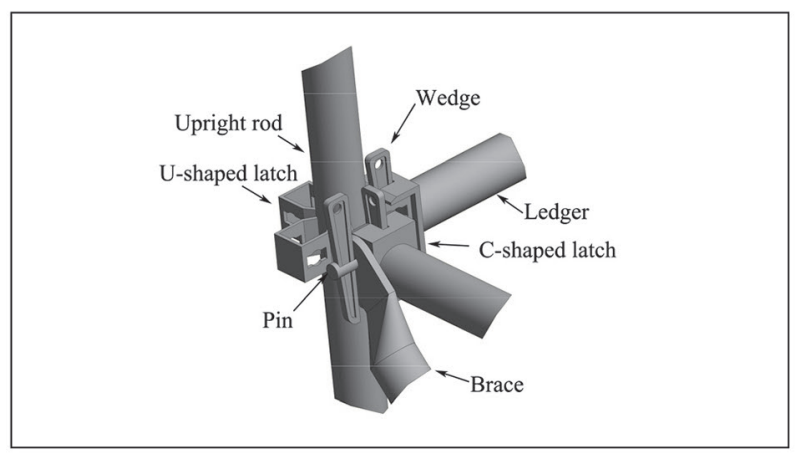

Figure 7. Plug-pin joint 


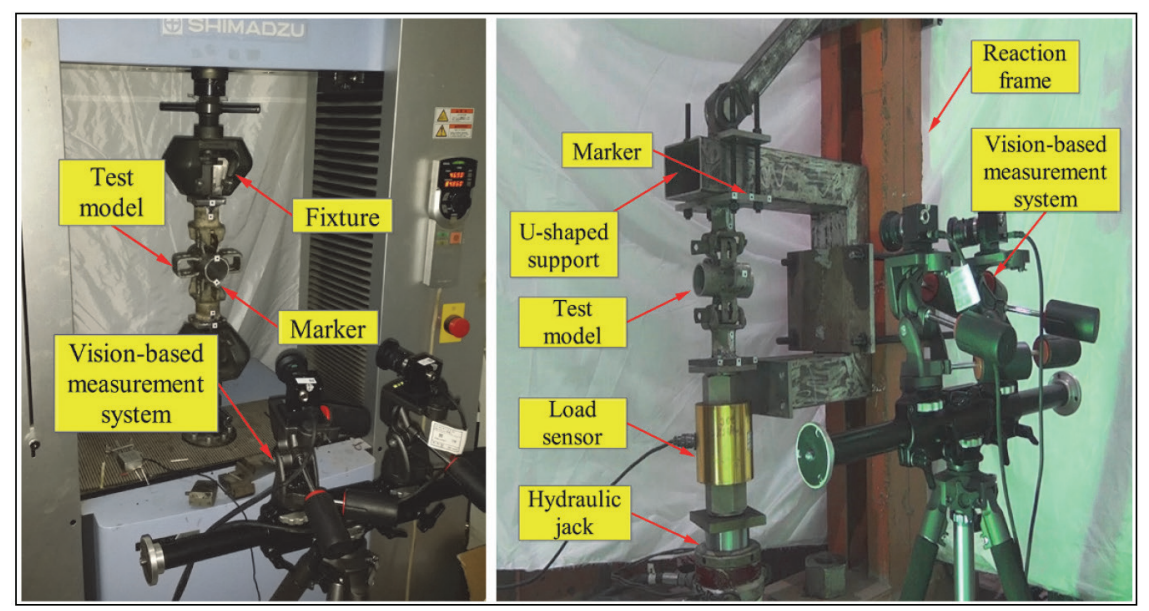

Figure 8. Test setups

U-shaped latch had two butterfly hooks on the side of it to connect to the brace end. The horizontal bars featured ends with C-shaped latches and wedges which lock into the U-shaped latch by wedging in. A wedge was also fixed onto the brace end using a pin with a butterfly-shaped end. In order to avoid installation failure, the construction error produced by the members and assembly workmanship could be adjusted by the different insertion depths of the wedges. Theoretically, every joint could connect four horizontal bars and eight braces while this was seldom the case in practice.

\subsection{Test setup}

There were 19 tests conducted in the lab, including three for horizontal bar joint tensile strength (HBT), three for horizontal bar joint compression (HBC), four for positive semi-rigidity between horizontal bars and vertical rods (PSR), three for negative semi-rigidity between horizontal bars and vertical rods (NSR), three for bracing tension (BTT) and three for bracing compression (BCT). HBT was completed by an AG-X plus tensile testing machine and others conducted by the U-shaped support, as shown in Figure 8.

For HBT, the ends of the test model were welded with a clamping piece fixed onto the tensile testing machine.
Markers were also attached to the surface of the joint to facilitate measurement by the vision-based measurement system and avoid the impact of slippage between the joint and fixture. A reaction system was applied for the other joint tests. A U-shaped support made from a $120 \mathrm{~mm} \times$ $80 \mathrm{~mm} \times 5 \mathrm{~mm}$ section of rectangular tubing was attached to the reaction frame which was mounted to the floor. A bracing with a $50 \mathrm{~mm} \times 40 \mathrm{~mm} \times 5 \mathrm{~mm}$ rectangular cross section was pinned between the U-shaped support and reaction frame to improve the overall capacity of the reaction system. A hydraulic jack capable of producing up to $300 \mathrm{kN}$ was attached with a load sensor and mounted onto a rail beam on the floor to apply loading. Two $10 \mathrm{~mm}$ thick plates were welded onto the end of the test model and connected with a U-shaped support and load sensor. The markers were attached to the test model and the measurement system was about one meter away from the test model.

\subsection{Test results}

The failure mode of each test, as well as the load and displacement (or moment and rotation angle) curve, was obtained, as shown in Figures 9-17. For the HBT, as shown in Figure 10a, the load $P_{\mathrm{T}}$ is applied to the pipe of horizontal bar, and the initial length of this joint $d_{0}$ is from upright

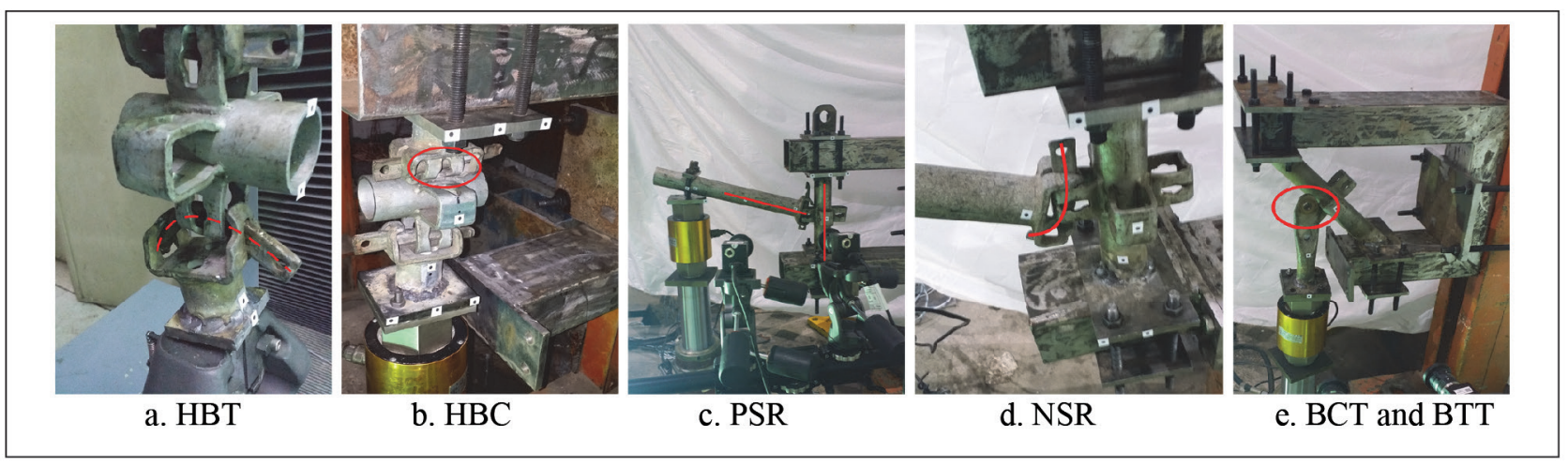

Figure 9. Failure mode for different conditions 


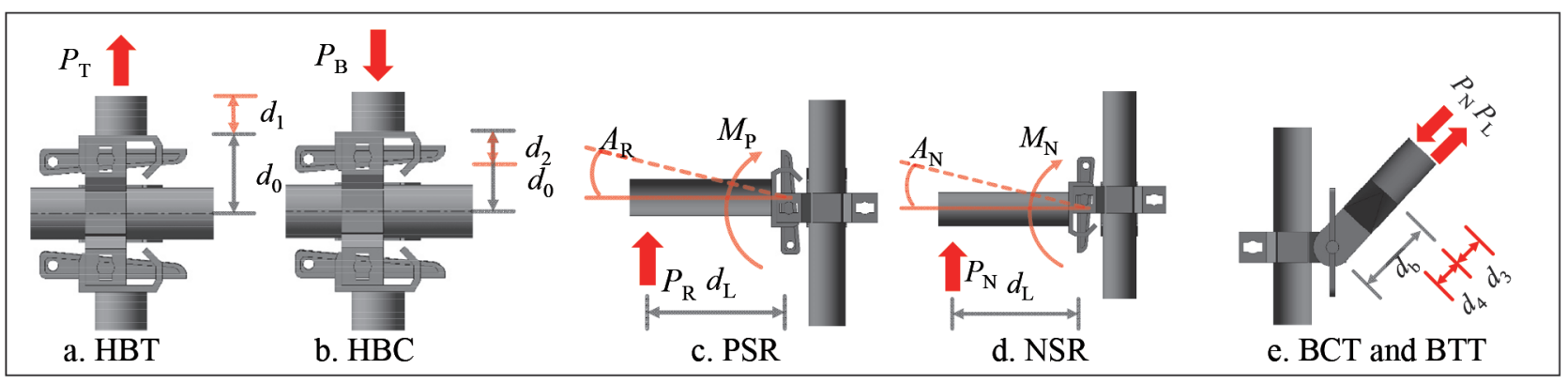

Figure 10. Describe of tests parameters

rod axis to the end of the pipe. The $d_{1}$ is the tensile length of the joint with the load $P_{\mathrm{T}}$. Two tests showed plug bending and another showed plug fracture failure (Figure 9a). The ultimate capacity was about $40 \mathrm{kN}$, and the displacement before failure was about $1 \mathrm{~mm}$ (Figure 11). So, the initial stiffness of the joint tension between the horizontal bar and vertical rod could be set at $4 \times 10^{4} \mathrm{kN} / \mathrm{m}$.

The U-shaped ears of the vertical rod joint showed buckling for the HBC, which was a ductile fracture (Figure $9 \mathrm{~b}$ ). The $P_{\mathrm{B}}$ is the compressive force and $d_{2}$ is the compression length (Figure 10b). When the load exerted $0-40 \mathrm{kN}$, the load-displacement curve (Figure 12) of each test was similar to linear displacement occurring from 0 to $1 \mathrm{~mm}$, indicating that the initial stiffness of horizontal bar compression was equal to the tension situation. For the load from $40 \mathrm{kN}$ to about $60 \mathrm{kN}$, the curves showed nonlinearity and the load led to the ultimate value.

The rotational stiffness between the vertical rod and horizontal bar showed varying performance according to the rotational direction. For the PSR, the moment $M_{\mathrm{P}}$ is created by exerting the force $P_{\mathrm{R}}$ on the horizontal bar with the distance $d_{\mathrm{L}}$ away from the connection joint (Figure 10c). The rotation angle of horizontal bar is defined as $A_{\mathrm{R}}$. The joint deflection was the rotation of the horizontal bar around the joint (Figure 9c), and the failure mode was not obvious. Plug bending was observed with the increasing of the NSR load (Figure 9d), and the loading method was the same as PSR. The $M_{\mathrm{N}}$ is the negative moment and the rotation angle is $A_{\mathrm{N}}$. As shown in Figure 13, the moment-rotation curves of positive semi-rigidity were similar to linearity without looseness at the moment from 0 to $0.6 \mathrm{kN} \cdot \mathrm{m}$, corresponding to the rotational angle varying from 0 to $0.05 \mathrm{rad}$. When the moment exceeded $0.6 \mathrm{kN} \cdot \mathrm{m}$, nonlinearity appeared until the moment increased to its ultimate value (about $0.8 \mathrm{kN} \cdot \mathrm{m}$ ). The ultimate rotation angle was about $0.15 \mathrm{rad}$. For negative semi-rigidity, the linear stage of the moment was from 0 to $0.4 \mathrm{kN} \cdot \mathrm{m}$, as well as the angle from 0 to $0.025 \mathrm{rad}$. The ultimate moment was about $0.85 \mathrm{kN} \cdot \mathrm{m}$, corresponding to an angle of $0.25 \mathrm{rad}$ (Figure 14).

The final failure modes were all plug brittle fractures for the BCT and BTT (Figure 9e). $P_{\mathrm{N}}$ and $P_{\mathrm{L}}$ are the loads applied on the pipe of the bracing. The $d_{3}$ is the tensile length and $d_{4}$ is compression length based on the initial joint length $d_{\mathrm{b}}$ (Figure 10e). For the BCT, three obvious

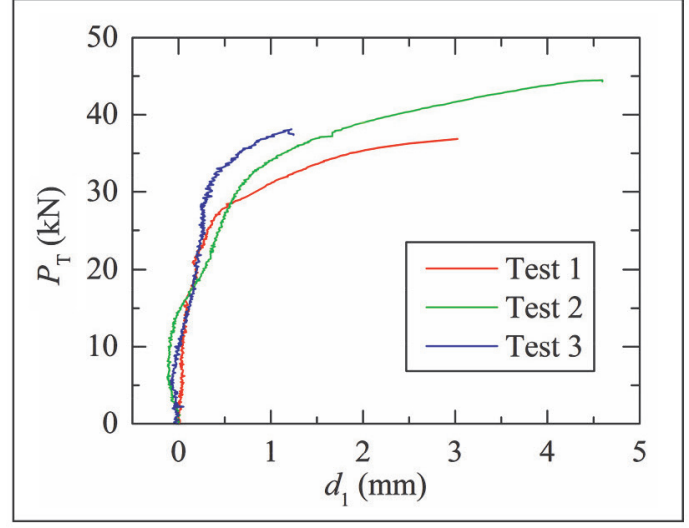

Figure 11. Load-displacement curve for the HBT

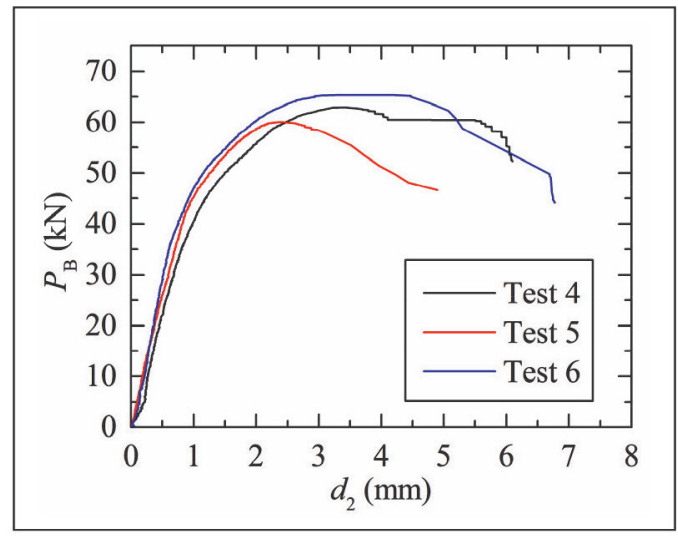

Figure 12. Load-displacement curve for the HBC

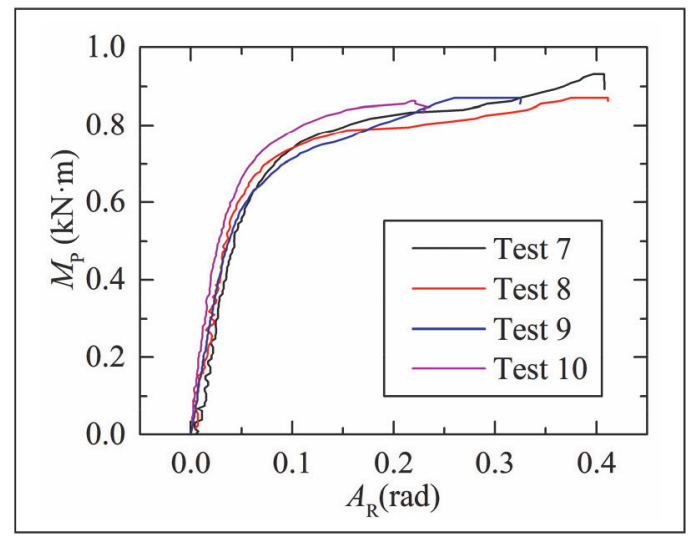

Figure 13. Moment-rotation curve for the PSR 


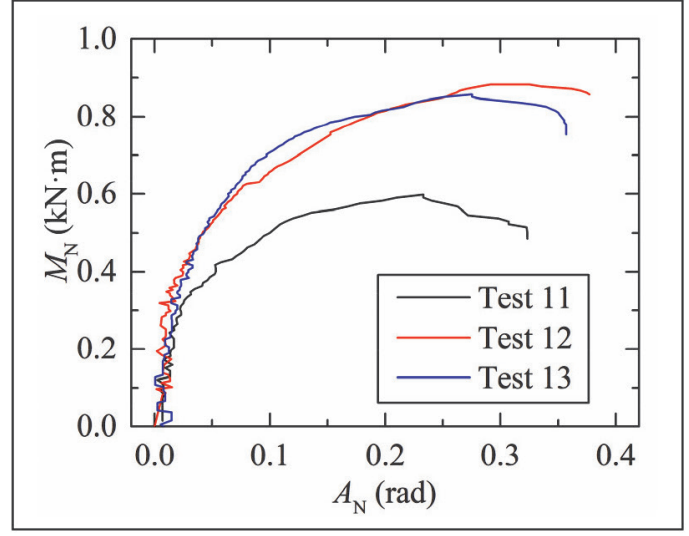

Figure 14. Moment-rotation curve for the NSR

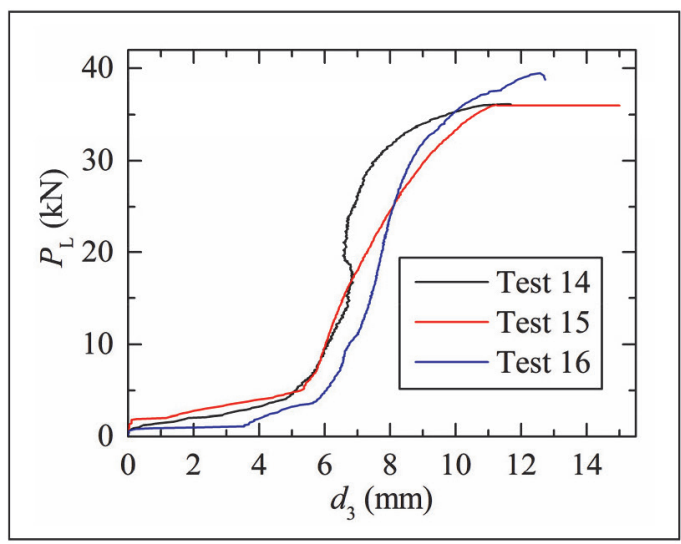

Figure 15. Load-displacement curve for the BCT

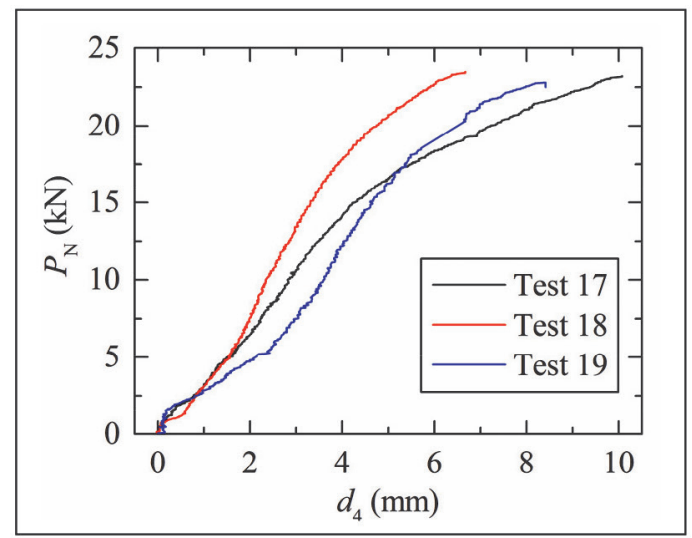

Figure 16. Load-displacement curve for the BTT

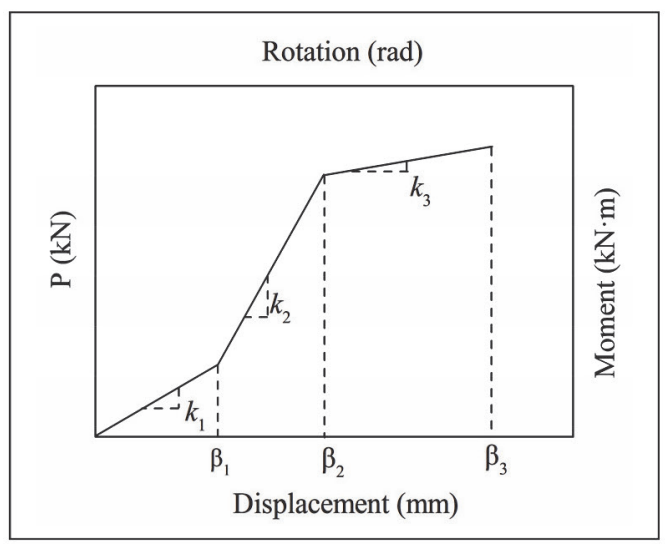

Figure 17. Multi-linear curve

stages happened as loads increased (Figure 15). Initial looseness was produced with little force, and the slipping displacement was about $5 \mathrm{~mm}$. The second stage was the load from 5-17 kN, with a displacement from 5-9 mm. The ultimate load was about $35 \mathrm{kN}$ and the displacement was $10.5 \mathrm{~mm}$. For the BTT, initial looseness also existed but was not obvious, as shown in Figure 16. The process can be divided into two stages. First is the load from $0-17 \mathrm{kN}$, with a displacement from $0-5 \mathrm{~mm}$. Then the loads increased until plug fracture occurred.

The tension and compression properties, and rotational performance between horizontal bars and upright rods, as well as the tension and compression properties of diagonal bracings, can be fitted by the multi-linear curve, as illustrated in Figure 17. "P (kN)" and "Displacement $(\mathrm{mm})$ " are used to describe the tension and compression properties, and "Moment $(\mathrm{kN} \bullet \mathrm{m})$ " and "Rotation $(\mathrm{rad})$ " are for the rotational performance between horizontal bars and upright rods. The parameters that describe the multi-linear curves are presented in Table 1 . In this paper, " $k_{1}$ ", " $k_{2}$ " and " $k_{3}$ " express the joint stiffness, while the " $\beta_{1}$ ", " $\beta_{2}$ " and " $\beta_{3}$ " represent the joint ductility. The " $\beta_{3}$ " for BCT and " $\beta_{2}$ " for other cases are the mean values of the displacement (or rotation angle) when the ultimate loads are reached.

The multi-linear curve of joint stiffness can provide joint parameters for the structural refined numerical model which is created for three-dimensional nonlinear analysis of the structure. As can be seen from Table 1, there are

Table 1. Parameters of fitted multi-linear curves

\begin{tabular}{|ccccccc|}
\hline \multirow{2}{*}{ Types } & \multicolumn{5}{c|}{ Parameters } \\
\cline { 2 - 7 } & $k_{1}$ & $k_{2}$ & $k_{3}$ & $\beta_{1}$ & $\beta_{2}$ & $\beta_{3}$ \\
\hline HBT & $73.34(\mathrm{kN} / \mathrm{mm})$ & $3.58(\mathrm{kN} / \mathrm{mm})$ & $/$ & $0.433(\mathrm{~mm})$ & $2.933(\mathrm{~mm})$ & $/$ \\
\hline HBC & $49.95(\mathrm{kN} / \mathrm{mm})$ & $11.49(\mathrm{kN} / \mathrm{mm})$ & $/$ & $0.868(\mathrm{~mm})$ & $2.85(\mathrm{~mm})$ & $/$ \\
\hline PSR & $13.17(\mathrm{kN} \cdot \mathrm{m} / \mathrm{rad})$ & $0.914(\mathrm{kN} \cdot \mathrm{m} / \mathrm{rad})$ & $/$ & $0.052(\mathrm{rad})$ & $0.311(\mathrm{rad})$ & $/$ \\
\hline NSR & $16.034(\mathrm{kN} \cdot \mathrm{m} / \mathrm{rad})$ & $2.161(\mathrm{kN} \cdot \mathrm{m} / \mathrm{rad})$ & $/$ & $0.028(\mathrm{rad})$ & $0.265(\mathrm{rad})$ & $/$ \\
\hline BCT & $0.795(\mathrm{kN} / \mathrm{mm})$ & $7.565(\mathrm{kN} / \mathrm{mm})$ & $2.025(\mathrm{kN} / \mathrm{mm})$ & $5.23(\mathrm{~mm})$ & $8.90(\mathrm{~mm})$ & $11.51(\mathrm{~mm})$ \\
\hline BTT & $3.569(\mathrm{kN} / \mathrm{mm})$ & $1.443(\mathrm{kN} / \mathrm{mm})$ & $/$ & $5.02(\mathrm{~mm})$ & $8.37(\mathrm{~mm})$ \\
\hline
\end{tabular}




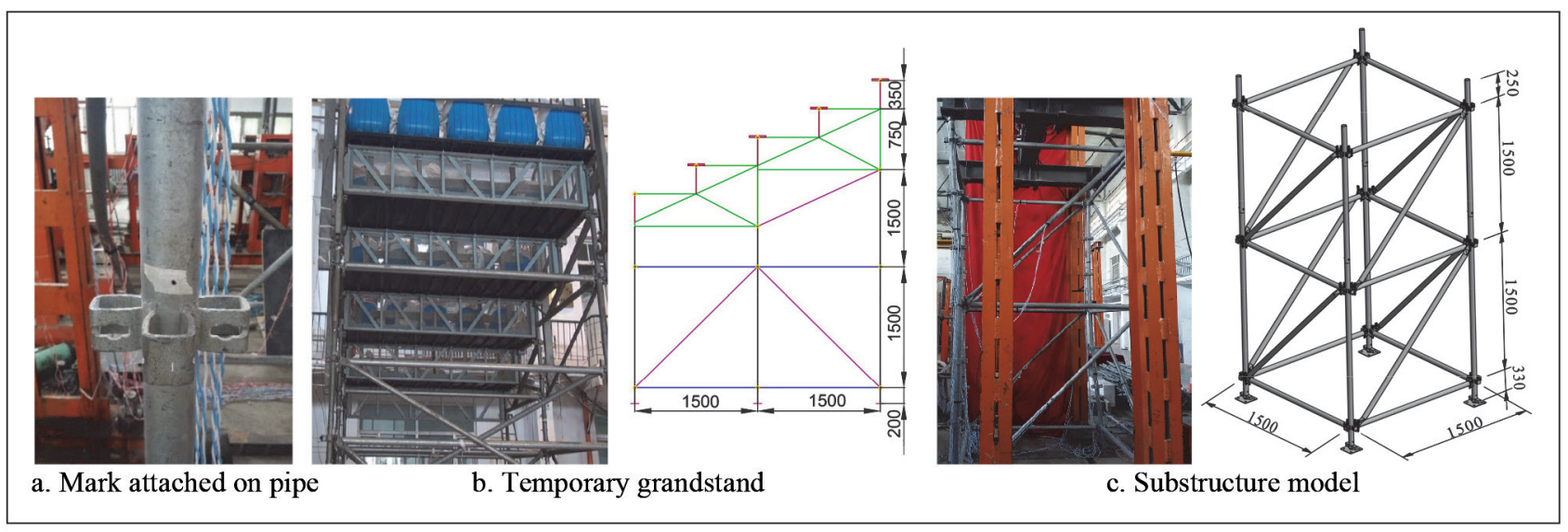

Figure 18. Mark attached to upright rod and measured temporary grandstand

similar joint stiffness for the tension and compression of horizontal bars. Compared with $k_{1}$ and $k_{2}$, numerical mutation happens for PSR and NSR, it can be assumed that the rotation stiffness has been lost when the rotation angle exceed $\beta_{1}$. The joint relaxation happens only in the case of bracing connection especially for bracing compression (the relaxation length of $5 \mathrm{~mm}$ ), and the difference performance between bracing tension and compression is more obvious.

\section{Investigation of geometric imperfections}

Member out-of-straightness was mainly affected by production quality and repeated use while story out-of-plumb was susceptible to member out-of-straightness, as well as issues with the quality of connection and on-site assembly. The members measured in this test were selected randomly and used several times. Before every test, members were assembled by different workers. Five marks were attached to every upright rod (Figure 18a). A total station theodolite was available to measure the three-dimensional coordinates of the marks, then upright rod out-of-straightness of and story out-of-plumb could be calculated. There were 91 measurements of upright rod out-of-straightness and 45 measurements of story out-of-plumb, including 11 substructure models and a temporary grandstand structure (Figure 18b and Figure 18c). The temporary grandstand provided 6 measurements of upright rod out-of-straightness without spigot joint, 2 measurements of upright rod out-of-straightness with spigot joint and 6 measurements of story out-of-plumb with the height $H=3.2 \mathrm{~m}$. For the substructure models, there were 44 measurements of upright rod out-of-straightness without spigot joint, 39 measurements of upright rod out-of-straightness with spigot joint and 39 measurements of story out-of-plumb with the height $H=3.33 \mathrm{~m}$. The geometric properties of components were listed in Table 2 . The cross sectional dimensions of members were measured and the mean values were adopted. When one of the tests was finished, the members were never used again.

The upright rod out-of-straightness value is the deflection at mid-height of the lift. The results of upright rod out-of-straightness were normalized with the layer height and the results of out-of-plumb were normalized using the height of the measured structure from the top mark to the bottom mark. Figure 19 shows the probability distributions and fitting curve of normalized upright rod out-ofstraightness without spigot joints, normalized upright rod out-of-straightness with spigot joints and normalized story out-of-plumb. The mean normalized upright rod out-ofstraightness without spigot joints is $0.0014(L / 714$, where $L$ is the member length.) with a standard deviation of 0.0008 and the mean normalized upright rod out-of-straightness with spigot joints is $0.0015(L / 667)$ with a standard deviation of 0.0008 . The mean normalized story out-of-plumb is $0.00227(H / 441)$ with a standard deviation of 0.0017 .

Both the mean normalized out-of-straightness of upright rods without spigot joints and normalized out-ofstraightness of upright rods with spigot joints show larger values than the maximum permissible out-of-straightness of $L / 1000$ in the Chinese design standard for safety of forms in construction (JGJ 162-2008 2008). The mean normal-

Table 2. Geometric properties of model components

\begin{tabular}{|c|c|c|c|c|}
\hline Types & Diameter (mm) & Thickness (mm) & Length (mm) & Slenderness ratio \\
\hline Upright rod & 48.35 & 3.25 & 1502 & 93.95 \\
\hline Bracing & 38.3 & 3.04 & $\begin{array}{c}2198 \\
2858 \text { (for grandstand) }\end{array}$ & $\begin{array}{l}175.66 \\
228.41 \\
\end{array}$ \\
\hline Horizontal bar & 48.48 & 3.15 & $\begin{array}{c}1492 \\
2493 \text { (for grandstand) }\end{array}$ & $\begin{array}{c}92.87 \\
155.18\end{array}$ \\
\hline
\end{tabular}




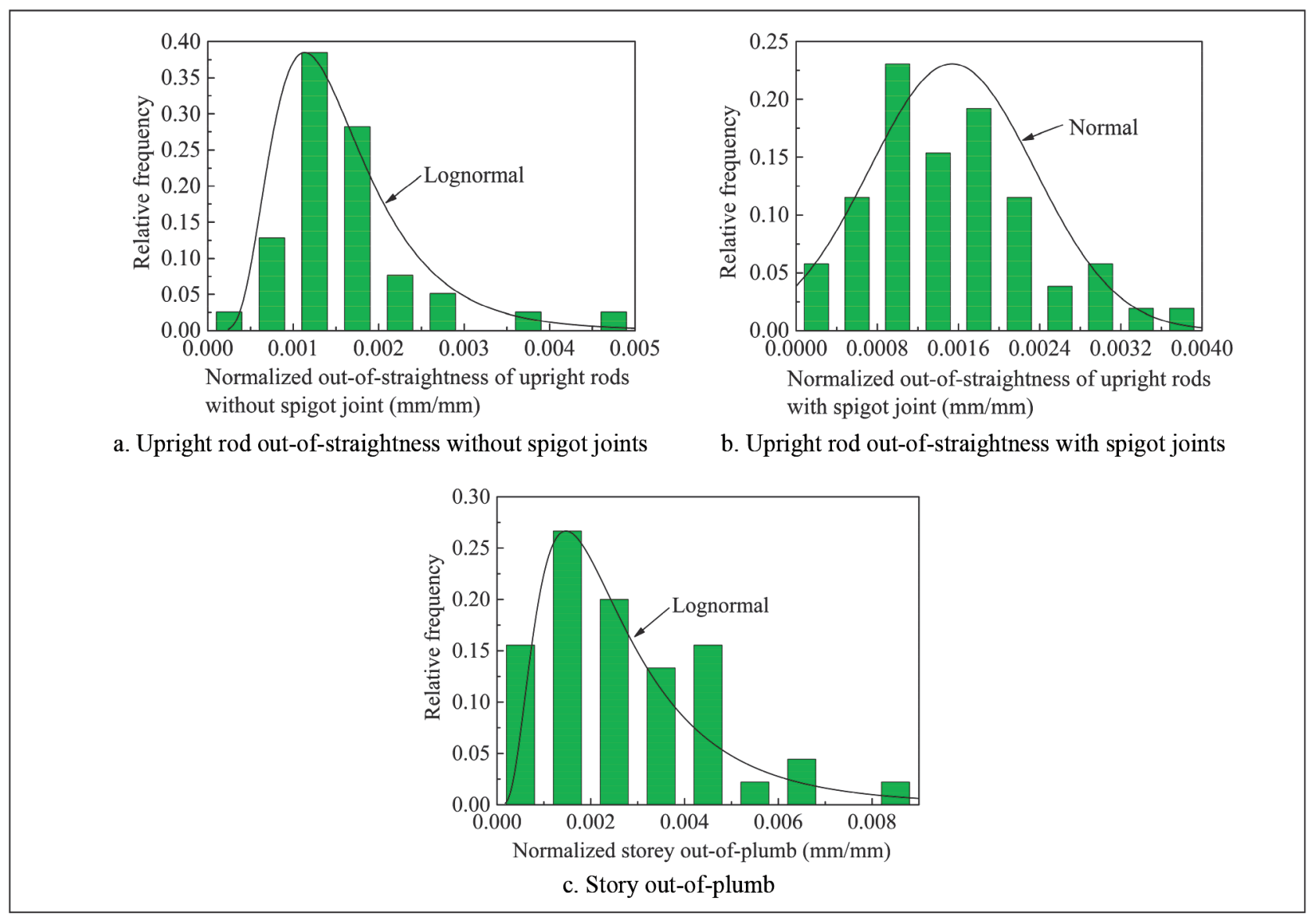

Figure 19. Probability distributions and fitting curve of normalized out-of-straightness and story out-of-plumb

ized story out-of-plumb also exceeds the maximum allowable out-of-plumb of $H / 500$ where $H$ is the height of the structure in the Chinese standard for steel structure (GB 50017-2003 2003). Then, it is not conservative to adopt the code value for modelling this structure with plug-pin joint and new regulations are needed to apply this structure. Compared with the survey results of scaffold systems with cuplock joints (Chandrangsu, Rasmussen 2011a), the TMS with wedge-type joints presents higher values of geometric imperfections, which may be caused by weaker joint connections and higher layer height. For plug-pin joints, the influence of spigot joints on upright rod outof-straightness is not obvious. The measured data can provide guidance for the modelling of TMS with wedge-type joints. Although different workers assemble the measured structures and their components are randomly chosen, more survey data of TMS with different sites and different structure types are needed.

\section{Conclusions}

In this paper, plug-pin joint stiffness was explored and 19 joint tests were conducted to obtain their mechanical parameters. A vision-based measurement system was developed to monitor the multi-point dynamic displacements for joint tests. The geometric imperfections of TMS with plug-pin joints were investigated using a total station theodolite. The probability distributions and fitting curves of normalized upright rod out-of-straightness without spigot joints, normalized upright rod out-of-straightness with spigot joints and normalized story out-of-plumb have been obtained.

The vision-based measurement method can reduce measurement errors compared with other displacement measurement instruments, especially when applied to joint tests that have small geometrical dimensions and several measuring points. Normalized cross-correlation can be used as the similarity measurement method for template matching, which meets the accuracy requirements of the joint tests well. The joint failure mode between horizontal bars and upright rods is ductile compared with brittleness between the bracing and upright rods. The rotational stiffness of the joint between upright rods and horizontal bars demonstrates different performance with different rotational direction. The multi-linear curve of joint stiffness, rather than simplified articulated model, can provide more joint parameters for the structural refined numerical model which is created for three-dimensional nonlinear analysis of the structure. It also makes it possible to consider the influence of joint stiffness on structural safety.

The stochastic numerical model can be established through probability distributions, which provides more realistic simulation of the service state of structure, especially for the structure with more serious geometric imper- 
fection. When the temporary member structure is applied to the grandstand or stage, a higher security is required and the accurate computational model becomes essential. TMS with wedge-type joints have higher values of geometric imperfections than with cuplock joints. More rules should be made to regulate the application of such structures.

\section{Acknowledgements}

This work was supported by the National Key Technology Support Program of China under Grant 2014BAK14B05. This support is gratefully acknowledged.

\section{Disclosure statement}

The authors declare that they do not have any competing financial, professional, or personal interests from other parties.

\section{References}

Armesto, J.; Lubowiecka, I.; Ordóñez, C.; Rial, F. I. 2009. FEM modeling of structures based on close range digital photogrammetry, Automation in Construction 18: 559-569. https://doi.org/10.1016/j.autcon.2008.11.006

Beale, R. G. 2014. Scaffold research - a review, Journal of Constructional Steel Research 98: 188-200. https://doi.org/10.1016/j.jcsr.2014.01.016

Bell, E. S.; Peddle, J. T.; Goudreau, A. 2012. Bridge condition assessment using digital image correlation and structural modeling, in Proceedings of the $6^{\text {th }}$ International Conference on Bridge Maintenance, Safety, Management, Resilience and Sustainability, 8-12 July 2012, Maggiore, Italy. https://doi.org/10.1201/b12352-41

Bielewicz, E.; Goórski, J. 2002. Reliability of imperfect structures (simple non-linear models), Journal of Civil Engineering and Management 8(2): 83-87.

https://doi.org/10.1080/13923730.2002.10531256

Chan, S.; Huang, H.; Fang, L. 2005. Advanced analysis of imperfect portal frames with semirigid base connections, Journal of Engineering Mechanics 131: 633-640.

https://doi.org/10.1061/(ASCE)0733-9399(2005)131:6(633)

Chandrangsu, T.; Rasmussen, K. J. 2011a. Investigation of geometric imperfections and joint stiffness of support scaffold systems, Journal of Constructional Steel Research 67: 576-584. https://doi.org/10.1016/j.jcsr.2010.12.004

Chandrangsu, T.; Rasmussen, K. J. R. 2011b. Structural modelling of support scaffold systems, Journal of Constructional Steel Research 67: 866-875. https://doi.org/10.1016/j.jcsr.2010.12.007

Chang, C.; Ji, Y. 2007. Flexible videogrammetric technique for three-dimensional structural vibration measurement, Journal of Engineering Mechanics 133: 656-664. https://doi.org/10.1061/(ASCE)0733-9399(2007)133:6(656)

Di, S.; Lin, H.; Du, R. 2011. Two-dimensional (2D) displacement measurement of moving objects using a new MEMS binocular vision system, Journal of Modern Optics 58: 694-699. https://doi.org/10.1080/09500340.2011.566636

Fu, G.; Moosa, A. G. 2002. An optical approach to structural displacement measurement and its application, Journal of Engineering Mechanics 128: 511-520.

https://doi.org/10.1061/(ASCE)0733-9399(2002)128:5(511)
Fukuda, Y.; Feng, M. Q.; Shinozuka, M. 2010. Cost-effective vision-based system for monitoring dynamic response of civil engineering structures, Structural Control and Health Monitoring 17: 918-936. https://doi.org/10.1002/stc.360

GB 50017-2003. Code for design of steel structure. Chinese standard, 2003.

Ghosh, P. K.; Mudur, S. P. 1995. Three-dimensional computer vision: A geometric viewpoint, Computer Journal 38: 85-86. https://doi.org/10.1093/comjnl/38.1.85

Godley, M. H. R.; Beale, R. G. 1997. Sway stiffness of scaffold structures, Structural Engineer 75(1): 4-12.

Jáuregui, D. V.; White, K. R.; Woodward, C. B.; Leitch, K. R. 2003. Noncontact photogrammetric measurement of vertical bridge deflection, Journal of Bridge Engineering 8: 212-222. https://doi.org/10.1061/(ASCE)1084-0702(2003)8:4(212)

JGJ 162-2008. Technical code for safety of forms in construction. Chinese standard, 2008.

Jiang, R.; Jáuregui, D. V.; White, K. R. 2008. Close-range photogrammetry applications in bridge measurement: literature review, Measurement 41: 823-834.

https://doi.org/10.1016/j.measurement.2007.12.005

Kala, Z. 2012. Geometrically non-linear finite element reliability analysis of steel plane frames with initial imperfections, Journal of Civil Engineering and Management 18(1): 81-90. https://doi.org/10.3846/13923730.2012.655306

Kala, Z.; Valeš, J.; Jönsson, J. 2017. Random fields of initial out of straightness leading to column buckling, Journal of Civil Engineering and Management 23(7): 902-913. https://doi.org/10.3846/13923730.2017.1341957

Lee, J. J.; Shinozuka, M. 2006. A vision-based system for remote sensing of bridge displacement, Ndt \& E International 39: 425-431. https://doi.org/10.1016/j.ndteint.2005.12.003

Liu, H.; Jia, L.; Wen, S.; Liu, Q.; Wang, G.; Chen, Z. 2016. Experimental and theoretical studies on the stability of steel tubecoupler scaffolds with different connection joints, Engineering Structures 106: 80-95.

https://doi.org/10.1016/j.engstruct.2015.10.015

Lord, J.; Mccormick, N. 2012. Digital image correlation for structural measurements, in Proceedings of the Institution of Civil Engineers - Civil Engineering, November 2012, Vol. 165(4): 185-190. https://doi.org/10.1680/cien.11.00040

Morlier, J.; Salom, P.; Bos, F. 2007. New image processing tools for structural dynamic monitoring, Key Engineering Materials 347: 239-244.

https://doi.org/10.4028/www.scientific.net/KEM.347.239

Peng, J. L.; Wu, C. W.; Chan, S. L.; Huang, C. H. 2013. Experimental and numerical studies of practical system scaffolds, Journal of Constructional Steel Research 91: 64-75. https://doi.org/10.1016/j.jcsr.2013.07.028

Tsai, R. Y. 1987. A versatile camera calibration technique for high-accuracy 3D machine vision metrology using off-theshelf TV cameras and lenses, IEEE Journal on Robotics \& Automation 3: 323-344. https://doi.org/10.1109/JRA.1987.1087109

Yun, C. B.; Lee, J. J.; Koo, K. Y. 2011. Smart structure technologies for civil infrastructures in Korea: recent research and applications, Structure \& Infrastructure Engineering 7: 673-688. https://doi.org/10.1080/15732470902720109

Zhang, Z. 2000. A flexible new technique for camera calibration, IEEE Transactions on Pattern Analysis \& Machine Intelligence 22: 1330-1334. https://doi.org/10.1109/34.888718 